\title{
Communicating self-care in feminist non-profit spaces
}

\author{
Emma Morris \\ Master's Research Project (MRP) \\ August 8, 2018 \\ Ryerson University \\ School of Professional Communication \\ Dr Jane Griffith, Supervisor
}




\section{Table of Contents}

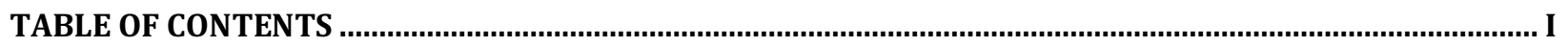

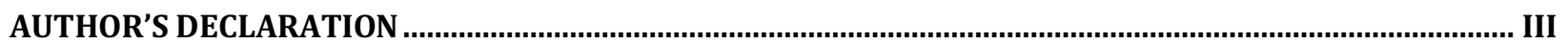

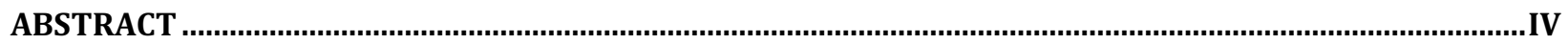

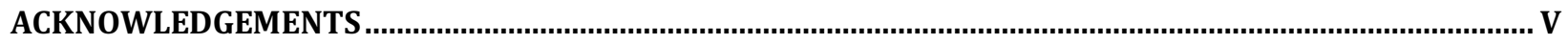

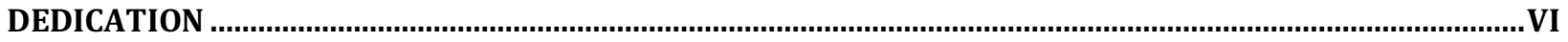

INTRODUCTION

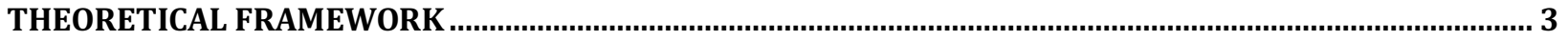

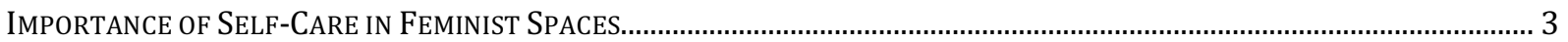

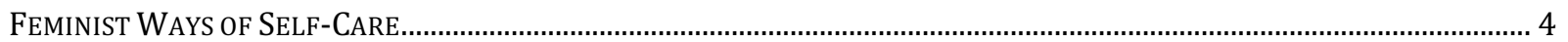

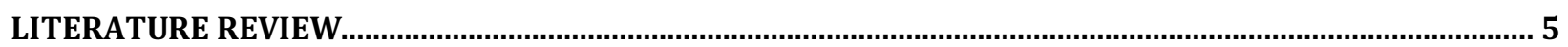

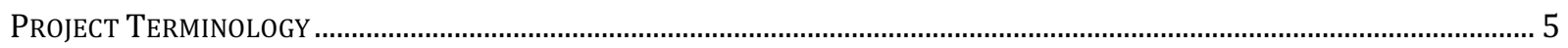

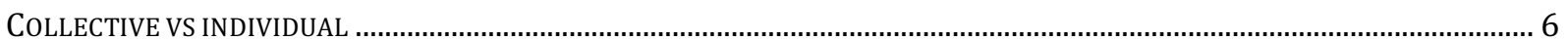

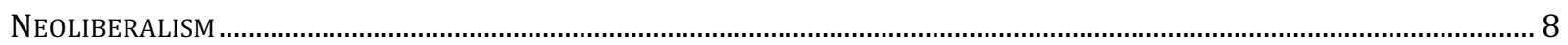

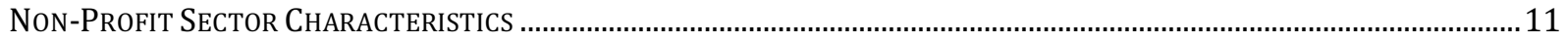

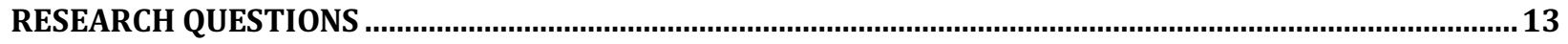

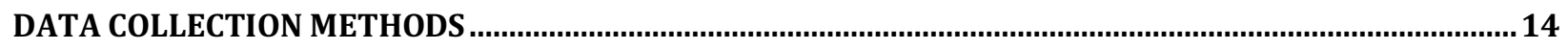

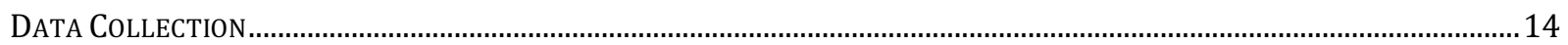

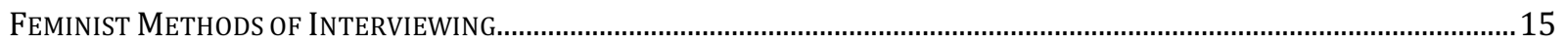

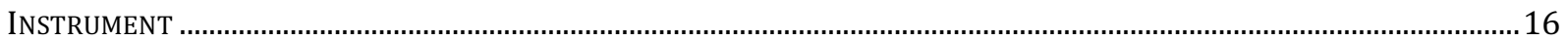

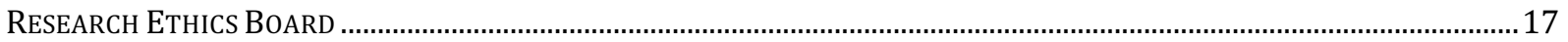

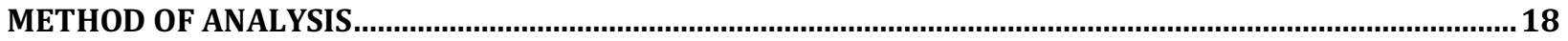

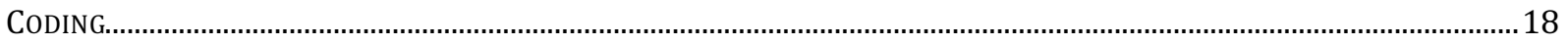

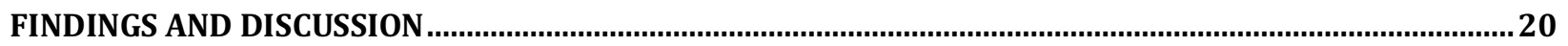

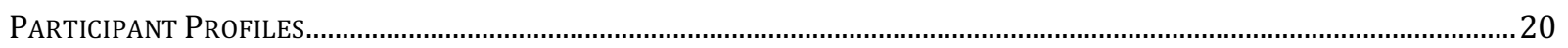

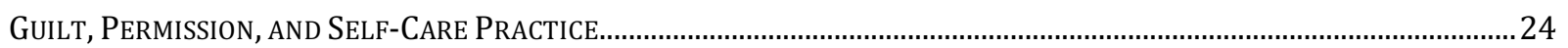

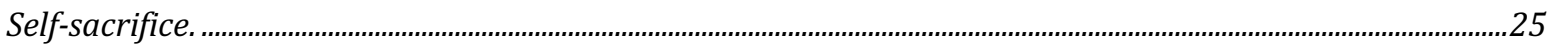

Guilt and resources: the question of "enough" .........................................................................................................26

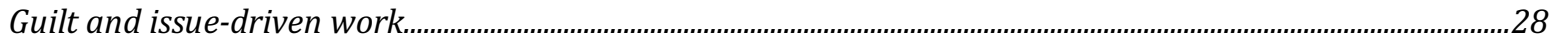

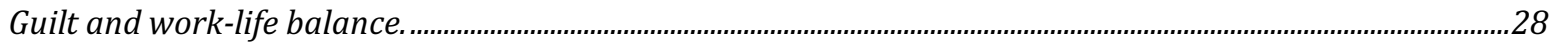

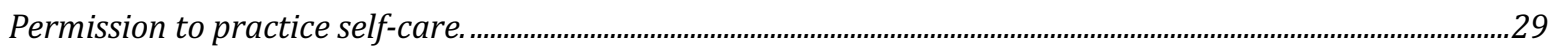

ColLective vs Individual: Society, FeminiSm AND SELF-CARE …...............................................................................

Society and self-care

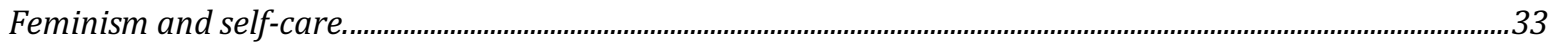

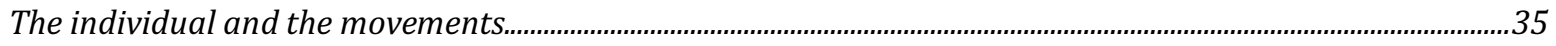

Money, Money, Money: The Funding-Self-Care RelationShIP..............................................................................

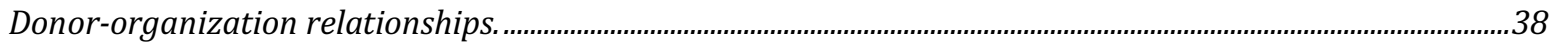

Overtime 


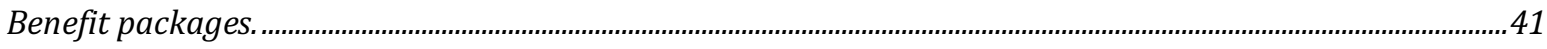

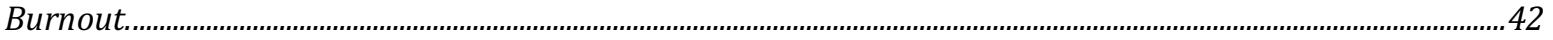

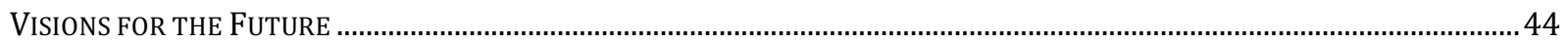

Knowing Me, Knowing You......................................................................................................................................................4

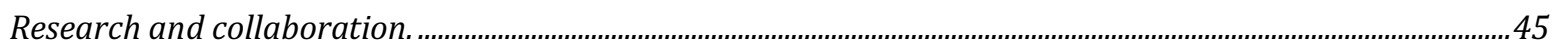

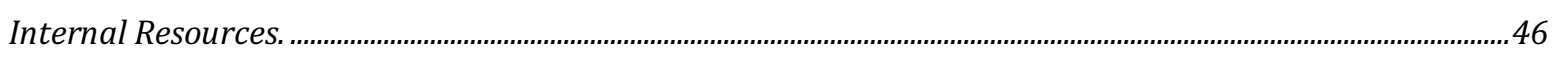

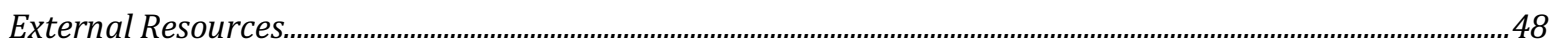

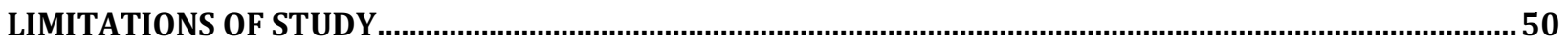

CONCLUSION

REFERENCES

APPENDIX A: INTERVIEW GUIDE 


\begin{abstract}
Author's Declaration
I hereby declare that I am the sole author of this MRP. This is a true copy of the MRP, including any required final revisions.

I authorize Ryerson University to lend this MRP to other institutions or individuals for the purpose of scholarly research. I further authorize Ryerson University to reproduce this MRP by photocopying or by other means, in total or in part, at the request of other institutions or individuals for the purpose of scholarly research.
\end{abstract}

I understand that my MRP may be made electronically available to the public. 


\begin{abstract}
Self-care is often used as a way for feminist activists and organizations to prevent or mitigate burnout, where non-profit organizations are expected to do more with less and pick up service delivery that has historically been the purview of governments. However, current scholarship on self-care in non-profit organizations typically focuses on non-profits in the nursing, mental health and social work sectors. This Major Research Project (MRP) examines women-focused non-profits (including shelters, legal clinics, and women's rights organizations) to investigate how these organizations frame self-care for their employees. Through qualitative content analysis of interviews with current and former non-profit employees, this project investigates how these narratives are perceived by those employees; what can motivate an organization to implement discussions of self-care; and how narratives of self-care change inside and outside of the workplace.
\end{abstract}




\section{Acknowledgements}

I would like to acknowledge the guidance, hard work, and constant encouragement of my supervisor, Dr Jane Griffith. I would like to thank Dr John Shiga for serving as second reader for this project. Last but certainly not least, I would like to thank my participants for sharing their time, experiences, and knowledge with me. 


\section{Dedication}

This MRP is dedicated to my incredibly patient and supportive boyfriend, Erik, who always reminds me of the importance of "just chilling". 
There must be those among whom we can sit down and weep and still be counted as warriors.

Adrienne Rich (1983).

\section{Introduction}

I don't remember when I first heard the term "self-care." The word crept up on me throughout my undergraduate degree: as I adjusted to the workload of university in first year, as I burned out in my third year, and as I frantically finished my honours thesis on the plane after attempting to take a week off over reading week in fourth year. When I had my first job in a nonprofit organization after graduation, I was lucky to work in an organization that openly talked about self-care in relation to the organization's work; to have the space to say "I'm not okay" after British Member of Parliament and activist Jo Cox was murdered for her political views. Over time, I had the sense that my experience was outside of the norm. I knew that other organizations did not talk about this topic in the same way or see self-care in the same way: as deeply personal practices essential to mental and physical wellbeing and particularly essential to activists.

Outside of the non-profit sector, I have seen the growth of self-care discussion online. Over the past five years, Google searches for the term "self-care" have risen consistently (Google Trends, 2018). On Instagram, 5,122,510 posts feature the hashtag \#selfcare and articles featuring recommendations on how to practice self-care can be found from most major news outlets, websites, and blogs (Gallucci, 2017; Kisner, 2017; Coles, 2018; Wax, 2018; Trombetta, 2018). The self-care "industry" is also growing —in the first three months of 2018 , the top ten grossing self-care apps earned \$27 million in revenue (Perez, 2018). In an interview with Queer Eye star Jonathan Van Ness on how to have a self-care "moment," Van Ness highlights a jade face roller, a $\$ 180$ hair tool, and headphones among items that one should purchase in order to 
create that moment (Mulkeen, 2018). Self-care in the Buzzfeed-era is full of face masks, capitalism, and memes. However, the same Google Trends that indicate a rise in searches for "self-care" also show a rise in searches for that term and "workplace." Non-profits are some of those workplaces that are integrating self-care practices, but the Buzzfeed method of self-care and its emphasis on consumerism is not always applicable to the non-profit workplace.

Self-care does not find its roots in the past five years: the term is rooted in Black feminist organizing in 1970s and is taken up in the works of Audre Lorde and Angela Davis. Feminist scholar Sara Ahmed considers Audre Lorde's work on self-care in a 21st century context in her blog Feminist Killjoys. As scholars such as Ahmed carry out academic work on self-care, feminist organizing continues to engage with the term and the issues surrounding it. Self-care is critical for feminist activists and organizations, where "burnout is the norm" (Ramsden, 2016). Even as the importance of self-care for feminist organizations is realized, non-profit organizations are expected to do more with less and pick up service delivery that has historically been the purview of governments. Current scholarship on self-care in non-profit organizations is growing and focuses on nursing, mental health and social work sectors. An examination of selfcare in feminist spaces has yet to be undertaken.

This Major Research Project (MRP) will examine women-focused non-profits (including shelters, legal clinics, and women's rights organizations) to investigate how these organizations communicate self-care to their employees. Through qualitative content analysis of interviews with current and former non-profit employees, this paper investigates how self-care is perceived by those employees; what can motivate an organization to implement discussions of self-care; and how self-care might be different inside and outside of the workplace. 


\section{Theoretical Framework}

This MRP is grounded in the theoretical framework provided by the writings of Angela Davis, Sara Ahmed, and Audre Lorde and their understandings of the role of self-care in feminist spaces.

\section{Self-Care in Feminist Spaces}

To be a part of a feminist organization is to work to change culture, laws, and practices while simultaneously combating marginalization. Self-care can help feminist activists continue to do this work. Audre Lorde writes, "as warriors, our job is to actively and consciously survive [a system of oppression] for as long as possible, remembering that in order to win, the aggressor must conquer but the resisters need only survive" (Lorde, 1988, p.95). However, that survival depends on taking care of ourselves, as survival is a long game. Lorde further highlights the particular importance of self-care for women of colour and marginalized persons working on feminist issues (Lorde, 1988). She writes, "rather than siphoning off energies in vain attempts to connect with women who refuse to deal with their own history or us, Black women need to choose the areas where that energy can be most effective" (Lorde, 1988, p.57). As Lorde articulated these notions of self-care's importance in the 1980s, Angela Davis echoes this in an interview in 2016. Davis shared that self-care and healing are now thought of as crucial parts of radical social justice movements (Gelder, 2016). Although clearly there was an awareness of self-care's importance in movements in the 20th century, there is now more discussion of the connection between one's self and one's organizing (Gelder, 2016). This importance of self-care in movements and organizing is echoed in Sara Ahmed's newest book, Living a Feminist Life (Ahmed, 2017, p.235). Ahmed highlights the importance of self-care in a feminist space as 
communal: as "what we do for others, with others" (Ahmed, 2017, p.235). This idea of self-care as a communal practice complicates the connotations of the word as an individual activity.

\section{Feminist Ways of Self-Care}

Ahmed's book concludes by laying out a "Killjoy Survival Kit" (Ahmed, 2017). This kit is a road map for feminists on how to take care of themselves - however it also highlights the subversive nature of taking care of one's self before others. She writes that when we turn these ways of care towards ourselves rather than others, "we are not caring for the bodies deemed worth caring about" (Ahmed, 2017, p.240). The survival kit further emphasizes that self-care is ordinary; it is looking after ourselves and each other and it is simply knowing that "time out is required for time in" (Ahmed, 2017, p.240). This survival kit is not prescriptive. Ahmed provides the reader her own toolkit for survival and follows this with suggestions of categories that one might include in one's own killjoy survival kit (Ahmed, 2017). This directive acknowledges that specific self-care practices are highly personal and determined first and foremost by the individual, even as these broader categories may be needed by everyone.

Lorde also echoes this in her writing by sharing the very ordinary ways that self-care can manifest in her life. She writes, "I must listen keenly to the messages my body sends" and that she is "learning to balance stress with periods of rest and relaxation" (Lorde, 1988, p.47, p.124). These ordinary moments of mindfulness are at odds with the commercial connotations that the word now has. These moments exemplify feminist self-care for women, particularly Indigenous and Black women, women of colour, women with disabilities, and trans women. 


\section{Literature Review}

\section{Project Terminology}

Prior to discussing scholarship on self-care, this paper first offers a working definition of self-care. Definitions of self-care vary by discipline and by author. Self-care can be defined as simply looking after one's personal well-being (Coster \& Schwebel, 1997, p. 11). On a macro level, self-care can be understood as "knowledge and awareness of hazards..., acceptance of those hazards and vulnerabilities [and] the need to incorporate and practice self-care principles" (Malinowski, 2014, p. 9-10). Self-care has also been defined as "inclusive of agentic selfregulated activities" - emphasizing the nature of self-care as something that is defined by the individual through knowledge of oneself (Bressi \& Vaden, 2017, p. 37). Self-care can be further broken down into the following subsections: physical, psychological, emotional, spiritual, and professional (Bloomquist, Wood, Friedmeyer-Trainor \& Kim, 2016). For this project, self-care will be broadly defined as practices and activities determined by an individual to best support personal well-being in times of stress or trauma, or as a preventative measure to support personal well-being.

The purpose of this project is to examine self-care in non-profit organizations. A nonprofit organization is defined as any organization that may not distribute profits to those who control it (eg. executive directors and board members) (Hansmann, 1980, p. 838). However, nonprofit organizations may "earn a profit" in the sense that they may end a fiscal year with a budgetary surplus (Hansmann, 1980, p. 838). There are many different terms for the non-profit sector as a whole, such as the voluntary sector and the third sector. For this project, I will refer to the sector generally as "the non-profit sector" and individual organizations as "non-profit organizations". 


\section{Collective vs individual}

Sara Ahmed writes about the importance of the collective when practicing self-care in a feminist space (Ahmed, 2017). Defining self-care as communal confronts the idea that self-care is a fully individual activity. The idea of the collective and the individual connects scholarship on self-care in the mental health and social work sectors with scholarship on non-profit organizations. On the side of the individual, scholarship on self-care and sectors such as mental health care and social work highlights the importance of self-care for practitioners in those fields. In the social work sphere, while practitioners know that self-care is important, research reveals that they often do not practice with self-care regularly (Bloomquist, Wood, Friedmeyer-Trainor \& Kim, 2016). The same research shows that the attitudes that one has towards self-care influence one's self-care practice-emphasizing the tension between knowledge by social workers of self-care's importance and the lack of putting that knowledge into practice (Bloomquist et al., 2016). Social workers engaged in physical self-care most frequently, while spiritual self-care activities ranked the lowest (Bloomquist et al., 2016). Social work scholarship also shows that whether or not self-care is currently being practiced, there is typically the feeling that one should be doing more (Shannon, Simmelink-McLeary, Im, Beecher \& Crook-Lyon, 2013). This scholarship views self-care a purely individual activity for which the responsibility rests on the individual.

In the mental health sector, self-care is viewed as critical for performing the duties of being a mental health professional (Coster \& Schwebel, 1997; Malinowski, 2014). To be successful, therapists must care for themselves before they can care for their patients (Malinowski, 2014). It is here that the other side of this dichotomy reflected - the collective coming to play a role in what seems to be an individual activity. When asked about wellbeing, 
psychologists identified eight out of ten themes around wellbeing that involved relying on other people (Coster \& Schwebel, 1997).

The tension between the collective and the individual is also present in scholarship on the non-profit sector. Such organizations have a distinct internal work culture that is very much linked to collective practices: a tradition of voluntary ethic, practices of strong relationships, altruism, participation, and physical and emotional care are just some examples (Baines, Charlesworth, Cunningham \& Dassinger, 2014). Scholarship highlights these characteristics of non-profit internal culture in the context of employee satisfaction at non-profit organizations, along with a sense of community and group participation (Weisberg \& Dent, 2016). These benefits often help to counter-balance comparatively lower salaries and potentially high stress work environments. Benz showed that "employees working at non-profit organizations are more satisfied with their jobs" due to these non-monetary benefits of working at a non-profit (Benz, 2005, p. 157). However, Baines et al (2014) highlighted the fact that some of these assumed practices of voluntary ethics may be reduced as the responsibility to monitor and document work shifts from the collective to the individual. As the individual is pushed to focus on outcomes and documentation of those outcomes, they are isolated from the actual impact of their workreducing some of the non-monetary benefits of non-profit work (Baines et al., 2014). The reduction of the collective practices shifts the historical "caring" nature of the sector and refocuses on an effort to retain financial support for an organization (Baines et al., 2014). Baines et al (2014) also found that self-care is a further problematic aspect of this new non-profit culture since employees are the ones who need to monitor their own well-being and seek out self-care practices on their own. Kamerāde and McKay (2014) also note that pressures of working at non- 
profit organizations extends beyond the workplace, meaning that employees who need to be selfreliant to prevent burnout will potentially be affected in their personal lives.

The collective/individual dichotomy is further present in alternative views of self-care practices themselves. Self-care can be more than simply a means to avoid difficult emotional experiences. One of the narratives present in the scholarship on social work and self-care is that self-care is a way of being moved by professional experiences. This disrupts the idea that selfcare might come about as a response that pulls the individual out of an intense emotional experience (Bressi \& Vaden, 2017). Rather, self-care can instead help an individual make meaning out of that emotional experience (Bressi \& Vaden, 2017). In the context of social work, where interacting with clients can bring about those intense emotional experiences, self-care is a way of processing those emotions (Bressi \& Vaden, 2017). In this alternative view of self-care, we see again that there is a clear emphasis on the individual and on retreating from the collective in order to do this work.

\section{Neoliberalism}

In scholarship on the mental health and social work sectors and the non-profit sector, the tension between the collective and the individual is further complicated by neoliberal views about self-care.

Scholarship indicates that no matter the sector, any initial education about self-care must be supported in the workplace (Bloomquist et al., 2016; Coster \& Schwebel, 1997; Shannon et al., 2013). Social workers and their employers view self-care differently (Bloomquist et al., 2016). Frequently, research revealed employers did not value self-care or effectively support self-care for their employees (Bloomquist et al., 2016). Moreover, when burnout is workplacerelated, the solutions suggested in the literature indicate that professionally driven self-care, 
based in the workplace, is the means to mitigate that burnout (Bloomquist et al., 2016). Taken together, these factors suggest that for some employers, self-care is important because it promotes a healthy workforce (Bloomquist et al., 2016). This assertion frames self-care in a neoliberal context, describing self-care as promoting productivity first and supporting personal wellbeing only as a secondary benefit. In some cases, this neoliberal framing extends to organizations viewing self-care as a practice that employees are "[given] permission" to do (Bell, Kulkarni \& Dalton, 2003, p.466). While institutions may frame self-care in this neoliberal sense, involvement of the institution is necessary to ensure that individuals are practicing self-care (Coster \& Schwebel, 1997). When interviewed, mental health professionals indicated that a profession-wide plan to develop a program of well-being was needed (Coster \& Schwebel, 1997). In a social work context, some Master of Social Work programs are taking on the task of teaching self-care to their graduate students (Shannon et al., 2013). However those graduate students indicated that specific training on self-care needs to extend to the workplace to further self-care training during their studies (Shannon et al., 2013).

For this project, the connections between self-care and neoliberalism are particularly significant in a feminist context as this project proposes to study women-focused or explicitly feminist non-profits. Rottenberg writes about the neoliberal feminist as "[accepting] full responsibility for her own well-being and self-care" (2013, p. 3). With specific reference to Sheryl Sandberg's bestselling book about women and leadership, Lean In, Rottenberg (2013) observes how liberal feminism is transformed to neoliberal feminism through the use of spaces in which women need to monitor themselves and their actions. Neoliberal feminism also distances itself from the kind of collective ideas present in Baines et al.'s study of non-profits (2014) by viewing changes in an individual's wellbeing as internal, individual, and outside of the public 
sphere (Rottenberg, 2013). Furthermore, the focus on the individual means that neoliberal feminism positions self-care in opposition to Angela Davis' concept of movement-based selfcare (Gelder, 2016). When writing about self-care, Audre Lorde tends to use "we" and "us" to again suggest self-care as a collective project—-this is also erased in neoliberal feminism's conceptualization of the term (Lorde, 1988). Self-care is becoming a neoliberal tool through the need for the individual to monitor their own well-being and carry out self-care practices when they need to (Bloomquist et al., 2016; Baines et al., 2014).

Neoliberalism and self-care can also be seen in the expectation by government that nonprofits will step up to fill the void left by the dismantling of public service. There is an increased interdependence between non-profits organizations and governments when it comes to service delivery (Salamon, 1995; Smith \& Lipsky, 1993). Governments want to cut their own budgets, while also have service delivery better suit the needs of their clients (Rasmussen, Malloy \& Agarwal, 2003). Governments suggest that local level services are able to do this better and more efficiently (Rasmussen et al., 2003). As governments back away from the expectation that they will provide social services, non-profit organizations also step into that void. Non-profit organizations and civil society advocate for a larger role for themselves (Brinkerhoff, 2002). Feminist organizations are particularly adept at this, advocating for the impact and effectiveness of grassroots feminist organizations and encouraging governments to fund those organizations directly (Nobel Women's Initiative \& MATCH International Women's Fund, 2017). In this context, the responsibility for "care" is shifted away from government and onto individual nonprofit organizations and civil society. The rise in dialogue around self-care occurs in a non-profit context as these organizations are expected to pick up where the increasingly neoliberal state ends - even as they are being defunded by those very governments. 


\section{Non-Profit Sector Characteristics}

One of the key features of the non-profit sector that distinguishes it from the for-profit sector is the gender makeup of its workforce. In Canada, the non-profit sector is $85 \%$ female, and this trend is also apparent in other countries (Baines et al., p. 370). As an industry, the non-profit sector is centered around the idea of care—historically regarded as a feminine characteristic in Western European traditions (Baines et al., 2014). Self-sacrifice is a gendered norm in the nonprofit sector-women are often the employees who take on unpaid overtime, and employers can exploit this resource as a result, intentionally or unintentionally (Baines et al., 2014). While women are the ones doing unpaid overtime, men in the non-profit sector often do not experience burnout in the same way that women do, nor do they report using any specific self-care practices to combat that burnout (Baines et al., 2014). In Kamerāde and McKay's study, they found that while both male and female non-profit sector employees did feel a higher level of fulfillment from working in that sector, women reported lower life satisfaction than men as a result of their non-profit employee status (Kamerāde \& McKay, 2014). The scholarship on women in nonprofit organizations has largely focused on the unique number of women in leadership roles at non-profits (English \& Peters, 2011). Within feminist non-profits, the high number of women in leadership roles often works against the implicit culture of inclusivity and openness (English \& Peters, 2011). The traditions of relationships and care (defining characteristics of non-profit organizations) perpetuate an environment where women in leadership roles silence the voices of younger women in the organization (English \& Peters, 2011). This reversion to hierarchical norms and turning away from feminist principles is often a result of stressful conditions within the non-profit - many of which are conditions that are unique to the sector (English \& Peters, 2011). 
In addition to gender, a distinguishing feature of non-profit organizations is the external pressures that impact organizational functioning (Baines et al., 2014; Weisberg \& Dent, 2016). These pressures include the stress of having to focus on outcomes rather than policy or social justice, difficulty in achieving those outcomes, meeting the requirements of funders, reliance on government funding, unpaid overtime, disparity of salaries between the for-profit and non-profit sectors, and lack of benefit packages (Baines et al., 2014; Weisberg \& Dent, 2016). These factors are frequently cited in studies on job motivation in the non-profit sector; however, other studies present an opposing view of the financial challenges that non-profit employees might face (Baines et al., 2014; Weisberg \& Dent). Benz writes that due to the definition of non-profit organizations (that they are prohibited from distributing profits to those in control of the organization), these organizations are saving money that can then be spent on programming, organizational administration, or employee salaries. In short, Benz suggests that these organizations can pay their employees more because they may not pay their board members (2005). However, studies such as this one are in the minority. Scholarship reflects a general trend that non-profits employees do not make as much as their for-profit counterparts because nonprofit organizations are unable to pay the same salaries as for-profit organizations (Baines et al., 2014; Weisberg \& Dent, 2016). 


\section{Research Questions}

This project on feminist non-profit organizations and self-care is guided by the following research questions:

1. What discursive strategies do non-profits use when communicating with their employees about self-care?

a. How are those strategies perceived by those employees?

This research question stems from the focus in scholarship on the need for institutions to take a greater role in promoting and teaching self-care (Coster \& Schwebel 1997; Bloomquist et al., 2016). I am interested in investigating how or if organizations promote self-care to their employees and the efficacy of the strategies used.

2. What conditions are necessary for an organization to incorporate self-care?

Baines et al. (2014) highlight the fact that women are typically the employees who undertake unpaid overtime, which employers often exploit. Bloomquist et al. (2016) highlight the neoliberal nature of self-care for employers. Rottenberg (2013) discusses the unique nature of self-care within feminism today. However, there are few studies on how employees in nonprofits use self-care practices. This question aims to investigate how discourses of self-care might be used in a women-focused non-profit.

3. What are the boundaries of institutional self-care practices?

Kamerāde and McKay (2014) suggest that working at non-profit organizations can affect employees outside of the workplace. If employees need to practice self-care to prevent jobrelated burnout, their personal lives may be impacted (Kamerāde \& McKay, 2014). This question aims to investigate whether such a spillover occurs, as well as if self-care is practiced differently inside and outside of the workplace. 


\section{Data Collection Methods}

\section{Data Collection}

Participants were invited via snowball sampling. Snowball sampling commenced online by reaching out with a recruitment email to contacts from my previous employment within the non-profit sector, as well as to contacts of my supervisor. From there, individuals contacted were asked to pass the recruitment email on to other individuals who may be interested in participating. Individuals who were interested in participating were directed to contact me via email. Participants had to be current or former employees of a women-focused non-profit organization (e.g. women's shelters, legal clinics, women's rights organizations, nongovernmental organizations working on women's issues) or had to have worked in a women/gender-focused role at a non-profit that does not necessarily have a specific focus on women. Individuals who have never worked at a non-profit were not eligible to participate in this study. Any demographic information that participants wished to share was included in the final data. However, demographic data was not formally collected. As my sample size was small, participants may have been less inclined to participate and to provide thorough information about their experiences if they believed their anonymity was at risk due to formal and lengthy demographic data collection. Any demographic data revealed during the interviews was used for coding purposes - for instance, to highlight the different experiences of an individual with a 20year career in one organization compared to an individual who had recently joined the non-profit workforce. Data was collected through five semi-structured interviews with current and past employees of women-focused non-profit organizations. Interviews lasted approximately 45-60 minutes and were audio-recorded. Five interviews were conducted in order to ensure that there would be time to interview, code, and meaningfully analyze all interviews. Interviews were 
conducted in a private room in Ryerson University's Rogers Communications Centre at 80 Gould Street or via video conferencing software such as Zoom, as well as off-campus locations of convenience to participants that still ensured visual and aural privacy.

\section{Feminist Methods of Interviewing}

My research questions centre on how employees at women-focused or feminist nonprofits perceive self-care in their organizations. Focusing on women-focused or feminist nonprofits demands feminist methods. Traditional interviewing practices stem from a masculine paradigm that sees the interview as an "instrument" of data (Oakley, 1989, p. 32). Feminist interviewing is different from other qualitative interviewing techniques because feminist principles of interviewing see the interview as a non-hierarchical relationship between interviewer and interviewee (Oakley, 1981). This non-hierarchical relationship reframes an interview as a joint process between the interviewer and the interviewee (Paget, 1983). My research questions allow for the interview process to be conducted without assuming to know the participant's experience; feminist interviewing builds on these research questions by constructing knowledge between me and the participant through the interview. Participants may ask questions of the researcher and the researcher's own identity is invested in the project, attempting to form an equal relationship between participant and researcher (Oakley, 1981). In RQ1, I established that I will be looking at what discursive strategies organizations employ and how those strategies are perceived. Looking at documents from organizations that detail how those organizations view self-care could have been a sole option for data collection however such documents are rare. In cases where they do exist, they are often not publically available. Interviewing provides both the discursive strategies employed and allows the interviewee to discuss how those strategies are perceived. 
This research also leans on Donna Haraway's concept of situated knowledges in the context of the researcher-participant relationship. In her efforts to complicate the idea of objectivity in a feminist sense, Haraway writes that "feminist objectivity means quite simply situated knowledges" (Haraway, 1988, p.581). Within the researcher-participant relationship, Haraway argues that "situated knowledges require that the object of knowledge be pictured as an actor and agent, not as a screen or a ground or a resource" (Haraway, 1988, p.592). For this research, use of Haraway's theory supports my choice to conduct semi-structured interviews. In a structured interview, the participant would not have as great of a chance to drive the direction of the interview; in contrast, a semi-structured interview allows greater opportunities for the participant to determine - along with the researcher - the nature of follow-up questions posed.

Feminist interviewing acknowledges that the interviewer invests their personal identity in the research (Oakley, 1981). Feminist interviewing does not claim to be fully neutral or objective. In the context of this project, my experience as a former employee of an explicitly feminist, women-focused non-profit informs this research and my interactions with interviewees.

\section{Instrument}

I conducted semi-structured interviews for this project. I established an interview guide based on my literature review and my research questions (see Appendix A for full research guide). Sample questions that were used in the interviews include:

1. How would you define self-care? What does it mean to you?

2. Does your organization discuss self-care? If so, how? (RQ1)

3. When did your organization first start talking about self-care? (RQ1)

4. Around what issues is self-care brought up in your workplace? (RQ2)

5. Are there additional ways you might discuss self-care in the workplace? (RQ2) 
6. Do you talk about self-care outside of work? How do those conversations differ? (RQ3)

\section{Research Ethics Board}

A Research Ethics Board protocol for this project was submitted on January 25, 2018.

The protocol was approved on March 9, 2018, which permitted research to begin on March 14, 2018. 


\section{Method of Analysis}

This project uses qualitative content analysis. I conducted interviews with five employees of non-profit organizations, which form the basis of content to be analyzed. I used the transcripts of these interviews in conducting my content analysis.

\section{Coding}

Once interviews were completed, I transcribed and anonymized the data. The interview transcriptions were then sent to participants to verify for accuracy and correct anonymization. I conducted qualitative content analysis, using the structure developed by Mayring (2014) for inductive category formation and coding. My research questions were intentionally developed to mitigate researcher assumptions of what the data will reveal about non-profits and self-caredetermining a deductive coding structure ahead of time would be at odds with these research questions. In keeping with principles of grounded theory (Strauss \& Corbin, 1990), inductive category formation was used. I first determined themes of coding categories and their levels of abstraction (Mayring, 2014). This deductive step was based on my literature review and research questions. I conducted a pilot interview to test the interview questions and collect sample data. The pilot participant fit the recruitment criteria and their responses, while not official data, were invaluable in shaping the project moving forward. I used this pilot interview and the sample data collected to begin formulating some coding categories, some of which were applied to the final research data.

Once final interviews had been completed, transcribed and anonymized, I coded the documents, working through the texts and determining categories based on the pre-established themes, and revising categories as needed (Mayring, 2014). I then conducted final coding and an intra-coder check (Mayring, 2014). 


\section{Findings and Discussion}

As is the case with qualitative interviews, many of the most interesting themes and statements from the interviews do not relate neatly to the initial research questions. The findings and discussion section is laid out thematically, with both findings and discussion presented concurrently. Participant experience highlighted guilt as a key deterrent to self-care practices. When these experiences arise, it is necessary to take up the question of how organizations may give "permission" to employees to practice self-care and how that permission may alleviate the feelings of guilt. Participant experience further centred on how society and feminism interact around the topic of self-care, including the ways in which self-care may become a tool of marginalization in an organizational setting. An examination of the non-profit sector necessitates a discussion of the ways in which funding affects the sector; participants shared how donororganization relationships, overtime, and benefits affect self-care. Looking at these fundingrelated factors also brought up a consideration of burnout in the non-profit sector. Finally, "Visions for the Future" will take up participant suggestions on how their and other organizations can improve their self-care policy and practice through research and collaboration; internal and external resources; and by promoting individual choice. This project will first turn to a profile of all participants, their organizations, and their experiences with self-care within current and former workplaces; setting the scene for the discussion that follows.

\section{Participant Profiles}

I recruited and interviewed five participants for this project. As the inclusion criteria was quite broad, participants came from a wide range of organizations, including women's shelters, national and international women's rights organizations, women's funds (non-profit organizations that fund women's rights organizations as intermediary funders) and large 
international development organizations. All participants and their organizations were located in Canadian urban settings. However, not all participants were working on issues within Canada. All participants were also full-time employees at their organizations.

Participant 1 worked at a small women's shelter in a large urban setting and believed that self-care was very important personally. While their organization did not have policy or training related to self-care, Participant 1 had participated in a self-care workshop at a previous organization, but this workshop was self-funded rather than paid for by the organization. Participant 1 indicated that they frequently initiated conversations with their colleagues about self-care and seemed to be the member of their organization most invested in self-care. Self-care at Participant 1's organization was present in the form of informal conversations amongst colleagues, and management was not typically involved in these conversations.

Participant 2 worked at a larger foundation focused on women's rights nationally. The organization has offices nationally, but Participant 2 is based in a large urban centre. Participant 2's organization does not have a top-down discussion of self-care. However, Participant 2 typically integrates self-care into projects on which they are the lead when the content of those projects is challenging. Participant 2 is in a supervisory role at their organization and they do not typically work front-line with clients in this role. Participant 2 also indicated that they have extensive volunteer experience in a front-line setting. In these roles, they have participated in self-care training as a part of more general volunteer training. This training was not a standalone workshop on self-care but was integrated into other training modules on supporting the emotional needs of clients.

Participant 3 is currently employed at a small non-governmental organization working on women's rights and has experience both in Canada and internationally in the women, peace, and 
security sector. Participant 3's current organization has some policy that implies an awareness of self-care (e.g. mention of need to take days off for reasons other than the illness of oneself or a family member) and implements check-ins on colleagues' wellbeing during staff meetings. Participant 3 has the most long-term knowledge about self-care and was aware of this concept (if not by the same name) in the late 1980s. While other participants may have equally long or longer knowledge of self-care, Participant 3 was the only participant to state that they had an extensive knowledge of self-care in the interview. Participant 2 had a similar understanding of self-care, both as a concept and a term, but has not worked in the feminist space for as long as Participant 3.

Participant 4 is employed at a larger women's shelter in a downtown, urban setting. Participant 1 and Participant 4 are the only two participants to work in the same type of organization-Participant 4 in a larger organization and Participant 1 in an organization serving women outside of downtown. Participant 4 has worked in shelter settings prior to their current workplace and indicated that self-care was not addressed as explicitly in former workplaces as it is in their current one. Participant 4's organization incorporated a great deal of events that involved all staff members as a form of self-care (e.g. community meals, staff appreciation, spa days, etc), in addition to more individual self-care supports such as benefit packages that included money for RMTs or a psychologist. Participant 4's organization identifies as feminist and works with a broad diversity of program participants. Participant 4's organization was also the only organization of all participants to formally include self-care in organizational policy. Participant 4 shared that their organization's new strategic plan will include a section focused on self-care, but they were unable to give any specific details about how self-care appears in this section. This section specifically related to self-care was a result of staff advocacy through the 
consultation process to have self-care included in the strategic plan. Inclusion of self-care in the strategic plan of an organization is rare across interview participants - no other participants reported that their organizations (current or former) made this inclusion. During the research phase of this project, I looked extensively for publicly available documentation from non-profit organizations that included mentions of self-care but was unable to find documents of this nature. With a small sample size, it cannot be conclusively said that inclusion of self-care in an organization's strategic plan is rare. However, it is rare across this project's participants.

Participant 5 works at a large international global aid and development organization in a senior policy role and has worked previously in women's rights organizations and development organizations. Like Participant 3, Participant 5 has worked internationally. Participant 5 currently works in a senior policy role at their organization. At their previous organization, they were responsible for the creation and implementation of a self-care strategy that included both day-today staff activities and program activities. This self-care strategy was a standalone document, but it was not part of organizational policy. Following this experience at their former place of work, Participant 5 has attempted to raise the importance of self-care in their current workplace. However, Participant 5's current organization does not have a formal inclusion of self-care in policy. Participant 5 shared that they believed self-care was important because they themselves had experienced intense burnout during their early career in the development field. Participant 5 was the only participant to explicitly discuss their own experiences of burnout.

Although the participants in the project come from different organizations, there were commonalities in terms of how self-care was discussed in their organizations. Participants frequently referenced conversations as the main form through which they discussed self-care in the workplace. While the interview guide contained questions that asked directly about policy 
documents, trainings, or formal meetings centred on self-care, the conversation remained the primary form in which self-care was present. For the purpose of this research, "conversation" refers to a formal or informal in-person discussion with two or more individuals that occurred in the workplace about self-care. Internal work cultures at non-profit organizations emphasize strong relationships (Baines et al., 2011). This emphasis provides a potential explanation as to why self-care is discussed via conversation in the workplace, allowing self-care to be brought up in a space of trust and relationship-building rather than through a top-down seminar or other instructional setting. While self-care does not appear through formal policy documents in this context, the conversation in a workplace setting does still represent professional communication.

One participant's experience of workplace conversations about self-care brought up the theme of guilt. This theme was reiterated, challenged, and expanded by most participants in this project. The prevalence of this theme across participants was unexpected and deeply interesting - this paper will now examine the ways in which this theme appeared in relation to self-sacrifice, resources, issue-driven work, work-life balance, and permission.

\section{Guilt, Permission, and Self-Care Practice}

Despite Audre Lorde's assertion that "caring for myself is not self-indulgence," self-care is often considered to be "selfish" (Lorde, 1988, p.130). This viewpoint is compounded in the non-profit context of this project where the sector is premised on the idea of caring for others while simultaneously grappling with a lack of resources. Feelings of guilt around taking time for oneself are even more common in this context. In numerous instances, participants named "not working enough" as the reason why they did not practice self-care or were conflicted about practicing self-care. In connecting non-profit work and self-care, several themes emerged: the 
idea of self-sacrifice; the question of what I am calling "enough-ness"; guilt associated with issue-driven work; work-life balance; and the idea of permission.

\section{Self-sacrifice.}

At its core, the non-profit sector is premised on the idea of care and giving oneself to others (Baines et al. 2014). Baines et al. (2014) highlighted the fact that self-sacrifice is a gendered norm in the non-profit sector. As neoliberal forms of feminism tend to position care as an individual responsibility, the self must then be sacrificed in order to provide that care.

Participant 1 shared that one of their colleagues was "very dedicated" to the work and never took time off. This dedication to the work came at the expense of this colleague's health, as they became very fatigued. Participant 1 shared that they and their colleagues spoke with their clients about self-care-however, in this example Participant 1 did not observe or understand their colleague to practice self-care. This example demonstrates a contrast between knowledge of self-care principles and practices and potential guilt over following through with those practices for themselves. Due to the fact that Participant 1's colleague talked to their clients about the importance of self-care, self-sacrifice may be something that one can recognize more easily in others than in oneself. Of the ways in which guilt plays a role in their own practices of self-care, Participant 2 shared, "it's hard to admit sometimes that you need a break from work that you feel like you have to be doing, [because] it's what you've chosen to do with your life in one way or another". Through the use of the verb "choose," this statement reveals how Participant 2 sees the work they do as more than just a job. Due to this viewpoint, stepping away to practice self-care is more fraught than stepping away from employment in which one engages only for monetary reasons. Viewing non-profit work as more than just a job feeds into the idea of job satisfaction, which is frequently brought up in discussions of non-profit work. Studies on job satisfaction in 
the non-profit sector indicate that lower salaries are "made up for" through the inherent fulfillment of non-profit work (Baines et al., 2014; Weisberg \& Dent, 2016). However, this project argues that fulfillment is not enough to mitigate the stressors of non-profit work that might lead an individual to require a self-care practice. Fulfillment can also be rephrased as “obligation". Even as Participant 2 sees non-profit work as more than just a job, they shared that the work was something they felt they "had to be doing"-demonstrating a sense of obligation. While it is work that Participant 2 stated was deeply meaningful, it can quickly become an obligation if an individual is consistently sacrificing themselves for an organization. As Participant 1 shared, this self-sacrifice can quickly have a detrimental effect on one's physical and mental health.

\section{Guilt and resources: the question of "enough".}

In a non-profit context, the question of "enough" is one that comes up around resources. When is the need for self-care funding enough? Is self-care funding available to employees enough to erase guilt over practicing self-care? Who deserves the limited funds available to a non-profit enough?

According to participants, time feeds into guilt on the part of employees when it comes to practicing self-care. Guilt is even more complex when those working in the space who hold privilege may feel even more guilty taking time off when they could be using that privilege to speak out or take action in some way. Participant 2 shared "how can I feel good about doing [self-care] when I feel like I'm not doing enough feminism?" There are two different sources of perceived guilt here: the practice of self-care and the amount of activism that the participant does. The amount of activism that an individual does determines their feelings of guilt attached to practicing self-care. When an individual cares about the issues on which they work, it is easier 
for work to encroach on personal time. If an individual chooses to leave work, that level of care can lead to feelings of guilt. In the case of Participant 2, this might mean attending protests or volunteering rather than stepping back completely from the work. Time and guilt connected to self-care are also tied to hours spent at work. Participant 3 shared that "the work never goes away no matter what you do. Sometimes you feel you're never doing enough". The feeling of not doing enough and the work not going away may cause an individual to spend more time at work, which again cuts into time that could be spent disconnecting and practicing self-care as needed. In addition to guilt over disconnecting from work to practice self-care, participants also shared feelings of guilt related to financial resources. Employees may not want to ask to access services or resources related to self-care from their organization if they know that the funding is either not present or that the need for that funding is greater elsewhere in the organization. Participant 2 stressed that "there's like a guilt cycle around that, like you might not even want to ask because otherwise you know that money is at least in theory going to go towards the people who quote unquote need it". This guilt might prevent employees from asking for funds related to self-care, when in fact the money may be available. Taking this one step further, money may not be allocated by management to self-care for a similar reason, as allocating that money away from programming would be taking money away from program participants. When budgets are made public or must be reported to donors, perception by the public or donors may influence the size or inclusion of a budget line for self-care. Both of these factors in turn may influence when, how, or even if employees are able to ask for self-care related funds.

While solutions will need to be determined by individual organizations, a potential way of framing conversations around self-care can be found in the work of Sara Ahmed. Ahmed writes that "time out is required for time in" (2017, p.240). While this quote is by no means a 
cure-all for the kind of guilt over time and money identified by Participants 2 and 3, it is a way of reframing time away from the work as something that will strengthen the work itself. Of course, this framing is done at the risk of bringing a neoliberal dimension into conversations about self-care - self-care is ultimately not about productivity but about personal wellbeing. However, this mindset is a point of consideration for organizations.

\section{Guilt and issue-driven work.}

In feminist non-profits, an organization may be working on inherently stressful issues. This stress may appear in working with vulnerable individuals, in a dangerous physical space, or on emotionally draining issues. Choosing to practice self-care when working on these issues is a further potential source of guilt. Difficult subject matter motivated Participant 5 to start a selfcare strategy at their organization. Working on these issues is often more pressing-when a participant's or client's life or wellbeing may be in danger, it may be easier to push self-care aside or experience guilt when one does choose to practice self-care. However, confronting these issues daily may lead to vicarious trauma if self-care is not practiced. Participant 5 was the only participant to acknowledge the potential effects of working on difficult issue-driven work. It is unclear whether this acknowledgement was implicit for other participants at their organizations. However for organizations for whom these issues of emotional or physical safety are a concern, there is a further layer added to the experience of guilt and self-care.

\section{Guilt and work-life balance.}

In Canada, the workforce of the non-profit sector is overwhelmingly female ( $85 \%)$

(Baines et al., 2014). The increased guilt felt by women who work in this space and may be caring for children, parents, or partners is a further barrier to practicing self-care. Participant 3 in particular shared an anecdote about a colleague at a former workplace. Participant 3's colleague, 
who was a mother, felt guilty that they typically left the office before Participant 3 (who did not have children at the time). Participant 3 intimated that there were times in life where one might be able to work more and other times (for example, when one has children) when one might have to leave early. However, it was this colleague's guilt that motivated a formal, organization-wide conversation about self-care. Guilt over leaving work early due to childcare responsibilities is a concern common to women, who are often responsible for the bulk of care work in the home. Furthermore, this guilt over being a mother is coming from feminist spaces, where theoretically more understanding and awareness of the diverse care responsibilities that fall to women should exist.

However, family can also be a source of self-care and a welcome break from focusing exclusively on work. The theme of guilt as stemming from a perceived conflict between family and work is complicated by Participant 5, who shared that for them, having a child meant that they had dedicated time in their days completely separate from the issues they work on. While this might not necessarily lessen the guilt of having to leave the office, it could provide a prescribed time that does not relate to work. From this viewpoint, self-care cannot be avoided when spending time with one's family.

\section{Permission to practice self-care.}

Acknowledging that this guilt exists, how can employees of feminist non-profit organizations begin a practice of self-care? One of the solutions identified through interviews with participants centred around the idea of permission. In some cases, organizations may frame self-care as a practice that employees are "[given] permission" to do (Bell, Kulkarni \& Dalton, 2003, p.466). For example, Participant 1's colleague only considered taking time off once they had been given "permission" through a reminder by Participant 1 to do so. If this guilt over time 
and resources is present, it provides an easy "out" for employees to push self-care to the side and continue focusing on what is considered most important. Furthermore, Participant 1's experience also shows that the success of self-care in a workplace environment depends on employees at all levels visibly demonstrating and discussing self-care and setting an example for peers and supervisors. Participant 5 echoed this when they stated that they felt organizational buy-in was necessary for people to "really see a difference". They shared that in their former organization, there was a "real commitment" from everyone to support one another. They believed that this level of support and commitment was what made self-care as successful in a workplace environment as it could be in a time- and resource-strapped environment. Although buy-in from the organization is ultimately beneficial in this case, it does still amount to permission from the organization to practice self-care. Through permission, self-care becomes institutionalized and moves further away from its roots in individual choice and radical self-love as Audre Lorde envisioned it. By moving away from these roots, self-care loses the meaning it has when it is a voluntary practice specific to the individual. When self-care is simply a box to be ticked, does self-care still carry the same benefits?

A further facet of "permission" to do self-care is the benefit packages offered by the organization. Almost all participants touched on their organization's benefit packages in some way during their discussions of self-care. In what ways can the inclusion of paramedical services such as counseling or massage be read as permission by the organization for the individual to practice self-care? Does the expansion of these benefit packages to include more mental health days, as wished for by many participants, become a form of permission from the organization for the individual to practice self-care? While generous benefit packages would be an important step forward for the sector, assessing how self-care is framed through inclusion in these benefit 
packages as prescriptive, permissive, or not present at all is a further entry point into examining the relationship between guilt and self-care.

What does the experience of guilt mean for practices of self-care in feminist non-profit workplaces? The emotional toll of guilt surrounding self-care practices may be alleviated through permission by the organization (through benefit packages, trainings, etc), but the practice itself then becomes complicated and risks institutionalization. There may not be a perfect way forward - however, acknowledging this guilt allows individuals and organizations to begin pushing back against the conceptualization of self-care as "selfish". We can then engage with a self-care practice that is inspired by principles reflected in Audre Lorde's work, respective of individual choice, and permissive rather than prescriptive. Thinking about a self-care practice in the tradition of Audre Lorde brings this project to consider the ways in which self-care might appear in a specifically feminist context, and into the next section of this project on society, feminism and self-care.

\section{Collective vs Individual: Society, Feminism and Self-Care}

What does it look like to take care of yourself, as a feminist, doing feminist work? This question was raised by multiple participants during interviews when discussing societally determined gender roles and emotional connection to the work of a non-profit. Participants also raised questions about how self-care might play into women's movements. This section will examine each of these issues and also return to the risks of institutionalized self-care to look at how this might further increase marginalization.

\section{Society and self-care.}

Societal factors can present a barrier to individuals' development of a self-care practice.

Individuals may be less likely to practice self-care if they believe that self-care is selfish. 
However, women may be even less likely to practice self-care as a result of this characterization. Participant 1 highlighted more broad, societal factors that impact those who identify as women in the context of caring for themselves. Participant 1 said, "we come from a patriarchal society where women have to work, [and] take care of other people". For Participant 1, patriarchy prevents women from being able to take care of themselves because they are expected to care for others. Participant 1 was the only participant to explicitly highlight women's roles as carers for others as a barrier to self-care; while other participants alluded to this barrier more implicitly, they did signal that it was as significant of an obstacle. Participant 1's emphasis on this barrier may be a result of their work as a frontline program provider who works directly with women program participants. Participant 1's experience and opinion of this barrier as significant is likely rooted in this work - as other participants are for the most part more removed from frontline work, this barrier may not be present in the same way for them. Despite the fact that only one participant explicitly discussed the relationship between self-care and patriarchy, this barrier remains significant as it demonstrates the ingrained, societally learned roles that inhibit knowledge and practice of self-care.

While self-care practices are determined by an individual, self-care did not emerge as a concept in a vacuum. The idea of self-care is collectively developed through communication about care over time. As noted, what Audre Lorde considered to be self-care is certainly not the same self-care represented in popular culture today. This difference shows the societally determined nature of self-care and demonstrates how an individual practice is developed collectively. 


\section{Feminism and self-care.}

The same assertion that self-care is selfish is further present in a feminist context. Within feminist work, participants discussed this barrier in a few different ways: as the level of care that feminists put into their work, as the deeply personal connection to the work, and as the relationship between the personal and the political.

Participant 3 highlighted the "feminist thing that we look after other people first before we look after ourselves". The non-profit sector is founded on this idea of caring for others. Participant 3 shared that caring for others before oneself is also a "feminist thing." Feminist nonprofits may then place an increased value on caring for others when the importance of care is doubly ingrained in their structure as both feminist and a non-profit. Participant 2 expressed that doing care work in a non-profit setting "feels natural" for individuals who are doing emotional labour in their personal lives. Participant 2 suggested that these individuals might call out this emotional labour in a personal context but might not do this in the workplace because the sector is premised on care. Participant 2 pointed out that when individuals engaged in non-profit care work did not "call out" this work, it would impact the sector on a systemic level. Sector-wide, feminists may continue to do this emotional labour in a workplace context even as Participant 2 stated that it was detrimental to the wellbeing of employees.

Participants also highlighted the deeply personal connection to the work that impacts selfcare practices outside of work. Participant 3 shared an example of that emotional connection, saying "we feel the blows of defeat or a mountain that we're not successful in climbing and we feel the highest when something goes right". This quote highlights the emotional attachment that individuals working in the feminist non-profit space often have to their work. These individuals often have intense emotional experiences as a result of the outcomes of their work, whether that be positive or negative. This deep emotional engagement might impact self-care for these 
individuals in a variety of ways. They may feel less in need of a self-care practice when their work is going well, and more in need when it is not going well. However, they may also feel the need to work more when they experience a defeat, tying this emotional connection back to the discussion of guilt. Participant 3 acknowledged that because of this deep level of care, it is "much harder to turn off caring at 6:00 when you leave work". In addition, reactive self-care (doing more self-care when a situation is already bad) may not be an effective long-term strategy. Audre Lorde highlights her own need to "balance stress with periods of rest and relaxation" (1988, p.124). Lorde suggests that those periods of rest and relaxation are necessary to get through those stressful times. For Lorde, these periods of rest and relaxation might have been a reactive strategy — however if rest and relaxation are necessary, completing them proactively will only support wellbeing during those stressful times. Sara Ahmed writes that "time out is required for time in" (2017, p.240) —and it is significant that she puts "time out" before "time in" in this sentence. Furthermore, self-care should be seen as a process rather than something that necessarily has an end. A reactive strategy that sees self-care only as a way to prevent burnout which is not necessary once the burnout has been "stopped" may not always be the most effective. These reactive strategies are not necessarily reflective of the way Lorde saw self-care; that is, in opposition to medicalized models.

For feminists, the work that one does is often deeply personal, making it more difficult to step outside of the work. Participant 2 shared that when the content and structure of the work is personal, the content often becomes more stressful and taxing because it may relate directly to one's own personal marginalization and experiences of inequalities. This personal connection may mean that participants engage in volunteerism on the same issues as their paid work, read articles about these issues, or discuss the issues with friends or family. Participant 2 questioned 
what maintaining "balance" might look like in a space where one's work is very personal. They used the example of CBC Radio host Jian Ghomeshi's acquittal of sexual assault as a particular instance that affected them in both their work and personal lives. Participant 2 indicated that their colleagues wanted to talk about the case as lunch room chat, while Participant 2 was working on a very emotionally challenging project at that time. Furthermore, their friends and family were talking about the case and media and social media coverage of the case was extensive. Participant 2 stated that the Ghomeshi case was their first experience "hitting a wall" and learning that they needed to clearly define for themselves when to tune out and when to tune back in to these issues on a personal level, since they could not always do so in the workplace. Participant 2's experience shows the level in which those working in the feminist space can be integrated into their communities and how difficult it may be to practice self-care when the connections between work and personal activism are so entrenched.

\section{The individual and the movements.}

Audre Lorde's best-known quote about self-care reads, "caring for myself is not selfindulgence, it is self-preservation, and that is an act of political warfare" (Lorde, 1988, p.130). Participants' guilt over practicing self-care shows that as much as this quote from Lorde is known and cited, feminist movements and organizations may not be putting it into practice across the board. Angela Davis noted that she has seen an increased integration of self-care into movements in recent years and an awareness of the idea that stepping away from the work to care for oneself is an inherently political, feminist act (Gelder, 2016). While this awareness of self-care as political did not appear in interviews with all participants, Participant 5 shared that they saw more of a push for the idea of self-care as political within women's movements currently in a response to "[everything] that's happening around the world". However, they 
believed that this push was only present in women's movements or in organizations that were led by women's rights activists. They suggested that there was a particular lack of self-care knowledge and practice in organizations working on development or humanitarian issues - many of which are working on gender-related projects. Participant 5 believed that for self-care to truly be integrated on a movement level, organizations from different sectors would need to share knowledge and collaborate on how best to achieve this.

In looking at self-care and feminism together, it is significant to go back to $R Q 3$ of this project which asked What are the boundaries of institutional self-care practices? Literature suggested that working at non-profit organizations can affect employees outside of the workplace (Kamerāde \& McKay, 2014). From participant experience, self-care in one's personal life can be related to issues from work when the work is connected to personal activism and emotional connection. In addition, individuals may work on an issue because of their own experience with that issue (e.g. working on violence against women having experienced it themselves). The practice of self-care itself (i.e. strategies used) may or may not be different when it is a personal or work related issue. When organizations are looking to help their employees who are experiencing heightened stress as a result of the interplay between personal activism and work, it is essential to look back at Participant 2's statement that work may be more stressful when it is related to one's own marginalization and experience of inequalities. In an organizational setting, self-care risks becoming a tool of further marginalization when it comes from a top-down approach. This top-down approach may come from organizational management, but it may also come from an organization's funders. The next section of this project will examine participant experience with funding in a non-profit context, self-care, and how donors may be able to play a role in shifting out of a top-down approach into a meaningful inclusion of self-care. 


\section{Money, Money, Money: The Funding-Self-Care Relationship}

For non-profits of all sizes, funding is typically precarious and necessitates making difficult choices by organizational leadership. As this project investigates the non-profit sector, participants did raise the issue of funding in their interviews. An organization's bank account may not always play into practices of self-care. However, examining discussions of funding by participants is important to a full understanding of their experiences of workplace self-care. Overall, participants indicated ways in which funding is a constant consideration in their own work. When funding comes to dominate conversations and decision-making in the workplace, the overall stress level of those decisions is raised — creating a space for self-care as a potential response. Funding concerns may also lead to increased workload and overtime for employees. In a worst-case scenario, this stressful working environment may lead to burnout. In addition, donors play a large role in the non-profit funding landscape, and their decisions determine funding. This section will investigate the ways in which funding considerations impact self-care, before touching briefly on burnout (an atypical experience in this study).

Some participants stated that funding for self-care was not specifically present in their organizations. As Participant 1 mentioned, when they completed training on vicarious trauma, this was done at their own expense. Participant 2 suggested that if there was more money available to a non-profit, it might be more likely that money would be spend on mental wellbeing-related benefits or self-care specific activities (including professional development, interpersonal supports, enhanced benefit packages, etc). From this, the question arises of whether self-care should cost money or be seen as something that needs to be funded. This project does not argue that one needs to spend money in order to practice self-care. As noted, self-care is fundamentally an individual practice and therefore subjective. For some individuals, self-care 
may require an output of funds, such as registering for yoga classes or taking a vacation. There is also a concern that self-care that is always tied to spending money is a capitalist move. However, in a workplace context the amount of money available to an organization does play a role in employees' experiences of self-care. The interaction between funding and self-care might involve benefit packages or overtime, and ultimately manifests in the tension between efficacy of programming and efficacy of staff.

While other organizations might consider making money the "bottom line", one of the participants in this study reframed this phrase in a way that is significant to non-profit organizations and to this project. Participant 2 shared that the bottom line might be considered as "helping people" in a non-profit organization. When the bottom line is helping people, what cuts are made to get there? What is considered as more important or less important? This new meaning to the phrase sets the tone for this discussion of funding and self-care.

\section{Donor-organization relationships.}

The relationship between funding and self-care begins at the source of the fundingwhich for many non-profits are donors. Whether individual, organizational, or governmental, donors and donor retention are central to non-profit work. However, there is often a fundamental disconnect between donors and organizations, whether in terms of needs, values, or goals. Participant 3 highlighted this disconnect in relation to self-care when they shared an interaction they had witnessed between a donor and an activist in the women's movement. Participant 3 shared:

One of the funders said, "oh, well we're really aware of self-care, we really believe in self-care. So we will fund mindfulness classes and yoga classes for the organization, things like that, for the organizations that we fund". And this woman on the other side of the room laughed and she took the mic[rophone] and she said, "well, instead of funding, you know, the odd yoga class, why don't you just give us enough money that we can pay decent salaries, hire enough people. 
That would be much more a contribution to self-care then funding a little yoga class here and there".

In Participant 3's experience, donors believe that funding wellness activities such as yoga is sufficient support for self-care. However, activists feel that in fact what is needed is simply more money for the organization to use to pay employee salaries. There is a fundamental disconnect between the donor and the activist about what is actually needed by the organization in terms of self-care. In addition, Participant 3 shared that for many organizations, lack of funding has created structural issues - for example, not being paid a decent salary is common at a non-profit, as is not having enough staff. These concerns are particularly evident in feminist non-profits. Self-care may also be weaponized to mark some of these funding issues. For example, spending money on self-care activities may cover up very low salaries and allow an organization to avoid a deeper examination of those salaries by pointing to self-care activities as evidence of their commitment to employee wellbeing.

The difference between restricted and unrestricted resources further contributes to the clash between funding and self-care. Participant 5 highlighted the fact that donors will most likely not provide funds specifically for self-care. While this might appear to contradict the example above, Participant 5's experience highlights the wide variance in donors in terms of what they will and will not fund. If donors will not provide funds specifically for employee selfcare or will only provide funding for self-care in ways that are not meaningful to the organization, then Participant 5 argued that unrestricted resources would better allow for selfcare funding. However, they also indicated that unrestricted resources also brought in the question of priorities and whether self-care was more important than program funding. Participant 5 stated that in their view, self-care would not be the most important priority. In 
addition to restrictions on resources for support, one participant highlighted that if self-care is not available to employees of an organization due to lack of funding, its availability for program participants may also be in question. Again, this concern brings back to the question of priority and just how deep seated the urge to put programming first can be in non-profits.

\section{Overtime.}

The urge to put program funding first is further reflected in discussions of overtime that arose during interviews with participants. Participants 2 and 4 in particular highlighted the fact that overtime is common in non-profit work. Overtime can refer to either physically working in the office after "normal" business hours, working at home after normal business hours, or working more time than was initially allotted in their contract. This overtime can also be a problem in that it is often unpaid in non-profit organizations. Participant 3 in particular indicated that overtime was significant in a feminist context where employees of feminist organizations care deeply about their work. As noted in this project's section on permission, caring about the work can make it easier for employees to take on overtime, particularly when there is knowledge of the fact that the work will not get done otherwise. Participant 3 stated that it is "much harder to turn off caring at 6:00 when you leave work" when there is a personal investment in the issue. Participant 2 concurred with this viewpoint, adding that they believed non-profits attracted people who would take on overtime voluntarily. They too suggested that this willingness to take on overtime was complicated in a feminist context (in particular, with unpaid overtime) and stated that this contributed to the devaluing of feminized work and care work when employees of feminist organizations were not compensated for all of the actual and emotional labour that is done. Overtime becomes a concern when the encroachment of work into personal time becomes overwhelming for an individual. Whether overtime is compensated or not, it can limit time 
available for self-care or can contribute to an individual's feelings of burnout. At the expense of self-care, participants' experiences seem to highlight that fact that it is often easier to simply take on more work rather than to insist on funding from donors that would expand staffing or ease workload in some other way.

\section{Benefit packages.}

One of the themes that emerged from interviews for this project in relation to funding and self-care was the role of benefit packages. Participants were clear to mention the specific benefit packages available to them and what they included. While benefits are not necessarily the same as self-care, benefit packages are defined as encompassing both medical benefits such as dental or pharmaceutical benefits, and benefits related to psychological services, access to registered massage therapists, and time off for sick days or paramedical days. While self-care is often in opposition to medicalized models, which Lorde discusses, participants indicated a blurring of the two. Participants 1 and 4 both highlighted their own use of these benefits for self-care. However they may not meet all individuals' needs for self-care and differ from organization to organization. Participants also typically indicated that benefit packages at non-profits tended to be more generous to make up for the smaller salaries - expanding on literature that noted benefit packages as less generous in some non-profit settings in both Canada and the United States (Baines et al., 2014; Weisberg \& Dent, 2016). However, participants tended to state that the content of these benefit packages was not always fully supportive of self-care. While self-care does not need to cost money, the contents of a benefit package might be a reflection of an organization's commitment to self-care. In larger non-profits that are unionized, these benefit packages may be bargained for by unions and therefore would not necessarily reflect a specific commitment to self-care by the organization. However, most feminist non-profits are not 
unionized. Some might say that benefit packages are a baseline that organizations would offer to their employees, but participants implied that benefits functioned as an indicator of whether or not their employer values self-care in the same way they (the employee) does. Participants who stated that their organization did not openly discuss self-care were all quick to then highlight the benefits that were available to them that supported their self-care. Although participants expressed a desire for greater discussion of self-care in their workplaces, they tended to feel that their employers were putting effort into self-care on the benefit side.

Employee access to benefit packages is determined by funding in that an organization's ability to hire full time employees is dependent on funding. Contract work is prevalent in the non-profit sector. If an organization is only able to hire contract employees due to precarious funding, those employees may not have access to any form of benefits. Lack of access to benefits by contract employees ties the relationship between funding and self-care back to donors — and highlights the role they can play in determining how self-care is present in women-focused nonprofits.

\section{Burnout.}

For some, self-care is a means to prevent burnout. Burnout was an atypical experience in this study_Participant 5 was the only participant to explicitly discuss their own experiences of burnout. It is not to say that no other participant experienced burnout, but simply to highlight the fact that no other participant chose to share that experience during the interview. Furthermore, experiences of burnout may vary widely across individuals and sectors. However, the experience Participant 5 shared complicates the funding decisions that non-profits may make. Participant 5 noted that when they experienced burnout, they were unable to work for a year. In fact, Participant 5 described the experience of burnout as being "mentally and physically 
destroyed". In this instance, burnout meant that Participant 5 was completely unable to continue working. In other cases, an individual may still be able to technically do their job, but Participant 5 was clear to highlight the fact that operating consistently at " $50 \%$ " would mean that an individual would be unable to bring their full potential to the workplace and to the rest of their life. In this context, organizations weighing what is "important" to spend money on risk losing their ability to impact their program participants through losing their staff. Programs can only go so far as the people who deliver those programs. When those individuals are too burnt out to work, the programs will suffer and be unable to deliver on promised outcomes-not to mention that those program officers are leaving the job "destroyed". At the same time, viewing individuals as resources and providing self-care only in order to ensure they are able to work demonstrates a neoliberal viewpoint of self-care as a means to increased productivity. In the research questions for this project, I asked what might motivate an organization to incorporate self-care in the workplace $(R Q 2)$. This motivation might be seeing individuals as resources and implementing self-care in order to ensure that the objectives of the organization can still be met.

Funding decisions are never straightforward and are constrained by fund availability, donor commitment and perceived need. However, funding does play a role in how self-care is present in a non-profit setting. This project previously discussed the presence of guilt about practicing self-care within non-profit organizations, and tied funding levels to guilt over self-care practices. Increased funding for non-profits may not eradicate this guilt or encourage individuals to begin a self-care practice. It also may not discourage organizations from using self-care practices only to prevent burnout. However, it may have the potential to alleviate some of the stressors associated with the sector and give organizations the opportunity to think about organizational sustainability and longevity—of which self-care is certainly a part. Considering 
organizational longevity brings up ways in which organizations may be able to adapt their current models of self-care inclusion, keeping employee preference in mind. To conclude the Findings and Discussion section of this project, I will take up participant suggestions for how feminist non-profits might deepen their self-care practices as organizations.

\section{Visions for the Future}

This project set out to investigate how self-care was communicated in the workplace. One of the unexpected outcomes of the interview process was the sheer number of ideas for how selfcare could be better reflected by organizations. Through the interview process, it became very clear that participants already knew what they wanted to see, both in their organizations and in the non-profit sector more broadly.

Returning to the definition of self-care from the beginning of this project, self-care refers to practices and activities determined by an individual to best support personal well-being in times of stress or trauma, or as a preventative measure to support personal well-being. This definition was carefully chosen to demonstrate that self-care is personal. While the concept of self-care may be collectively developed, self-care practices are set by an individual. While this definition within a workplace is complicated in practice, it is reiterated here as a reminder that organizations considering these visions for the future should not view them as a prescriptive plan for a successful self-care strategy.

\section{Knowing Me, Knowing You.}

These visions for the future begin with participant suggestions highlighting the need for individual choice. This need was brought up by multiple participants. Participant 3 suggested that ideally, inclusion of self-care in the workplace would include something that went "beyond the obvious" and that could incorporate some form of individual needs assessment. Participant 3 
also highlighted a need for "exploration" by employees, which once again underscores this idea that an individual should define what effective self-care is for them. In an organizational setting, exploration might mean presenting a range of options for taking vacation days or offering working from home as an alternative to taking days off. Participant 5 stated that more resources on self-care specific to non-profit feminist work were needed. Participant 5 did not define any specific resources, and this choice not to name specific resources may be further reflective of the importance of individual choice. A resource that works for one individual or one organization may not work for all. However, Participant 5 was clear to state that at this time, there are no selfcare resources that are specifically developed with the non-profit sector in mind (for example, workshops that take into account funding concerns and organizational culture).

Although self-care is defined in this project as being rooted in individual choice, participant testimony highlighted the ways in which self-care as individual may be problematic. For example, a top-down approach to self-care within an organization risks the institutionalization of self-care. Over-emphasizing individual choice to the point that self-care becomes the responsibility of the individual alone might transform self-care into a neoliberal tool to increase productivity. Balancing organizational buy-in and support for self-care with providing a wide array of options (supported by the organization) for individuals to choose from may be a key challenge for organizations looking to meaningfully integrate self-care.

\section{Research and collaboration.}

A lack of self-care resources for organizations may stem from a lack of research on this topic. Participant 5 shared that when they were in the process of developing a self-care strategy for their former organization, they were unable to find a great deal of literature on how to mitigate the impacts of work on NGO workers. They were also unable to find an organization 
that had a self-care strategy. Participant 5 had an intern who was a social worker and was able to help with access to resources, but those resources were not always relevant to the sector in which Participant 5 was working. The lack of sector-specific research and resources supports my own literature review that most of these resources and research are found in the social work or mental health sectors. To mitigate this lack of research, Participant 5 stated that working with other sectors such as academia, social work, psychology and occupational therapy would be a first step. Participant 5 stated that the NGO sector would not be able to figure this out by itself. However, Participant 5 also shared that they did not believe that there would be any great changes in the next 10 years, due to issues (particularly in the NGO sector) such as sexual exploitation and abuse of both workers and program participants. These issues are not competing with self-care — and could relate very deeply to self-care - however, they are more immediately pressing for the sector as represented by this participant.

\section{Internal Resources.}

Similar to participants' mention of conversations as the main form in which self-care was discussed in the workplace, they also highlighted conversations as a potential vision for the future. Participant 2 shared that for them, conversations on difficult topics and how they could impact an individual might bring up reflection on one's own experiences. They added that this reflection might be able to open doors for individuals to feel comfortable sharing that they were burnt out, triggered, or feeling in need of self-care in some way.

Participant suggestions also returned to some of the themes apparent in existing discussions of self-care. Participant 2 said that individuals might feel shame about feeling burnt out or in need of self-care - tying this solution back to the ways in which individuals experience guilt about practicing self-care. For Participant 2, engaging in an ongoing organization-wide 
conversation about self-care might give individuals the opportunity to open up. This suggestion also ties back to the idea of "permission". In this instance, Participant 2 specifically said that individuals could be "given permission to talk about the way the work impacts you". While these structured conversations might indeed bring about a more open dialogue, there is again the risk of self-care becoming institutionalized in this way. As participants indicated, discussions about self-care in the workplace are primarily conducted through conversations currently. As conversations are an established method, they may be the best way for organizations to begin a self-care strategy. However, careful attention must be paid to how these conversations occur. For example, excessive moderation of dialogue might not be the most meaningful way to discuss something that is inherently individual.

For this project, only one participant noted that their organization included self-care in their strategic plan. This inclusion came from advocacy by employees. Participants suggested that inclusion of self-care in governance or organizational policy as a way to include self-care in policy decisions. Participant 2 shared that they felt there was a need on a governance level for there to be an acknowledgement of the fact that non-profit work asks more of individuals than other sectors. However, including self-care in policy is something that can very quickly become a top-down approach to self-care. Policy that requires individuals to tick off a "self-care box" cements self-care within the institution — individuals may see self-care as a chore rather than a meaningful practice. Participant 4's workplace may provide a potential way forward to include self-care in policy: beginning with a bottom-up approach based in staff advocacy, followed by staff writing this policy themselves. 


\section{External Resources.}

A potential follow-up to a conversation could be a workshop. A few participants mentioned a workshop as something that might interest them. The desire for workshops can be read in a few different ways. It could indicate that individuals want to grow their own self-care knowledge and feel that an instructional environment would be the most beneficial to them (rather than seeking out information on their own). In other cases, an individual might believe that their colleagues would benefit from a workshop or that based on the nature of their work or their organizational structure, learning as a team would be the most effective strategy. However, Participant 3 presented a counter-argument to workshops when they stated that they believed it would be "a waste of time" to pull people out of their work day for a discussion of self-care. Considering that participants expressed feeling guilty over spending time on self-care and not working, it is interesting to note that participants also expressed this desire for a workshop. Weighing the cost and benefit of a workshop and balancing a desire to learn more about self-care with this expressed guilt over taking time away from work is one consideration that comes with workshops. Individuals may feel guilty when self-care is conducted on their own time in their home; a workshop during work hours might lessen that guilt as self-care is institutionalized in the workplace. A further consideration is whether self-care is something that can be taught in something such as a workshop — or if a workshop might imply that once learned, one can practice self-care perfectly all the time. Workshops risk packaging self-care and selling it as a way to reach a perfect iteration of self-care.

What does it mean to reduce self-care to something that can be learned in a workshop? Sara Ahmed's Killjoy Survival Kit provides a potential way forward (2017). The Survival Kit is not prescriptive. It does not provide individuals with neat boxes to tick off with skills to learn 
and objects to have. It simply presents suggestions of what might work, what might not workin other words, jumping off points for further reflection.

Participants also mentioned counselors as a further external resource. Participant 2 was very clear that these counselors should be external (i.e. not an HR employee of the organization). Offering counseling could give employees the opportunity to talk about the impact of doing nonprofit work and give them a sense of what further resources could be available to them.

Participant 3 suggested that perhaps having someone to talk to one-on-one might better allow for individuals to have a focus on self-care. Keeping this individual focus could help mitigate some of the concerns brought up by workshops. Allowing individuals to schedule these check-ins on their own time (rather than having to take time out of the work day) may help prevent self-care from becoming a top-down approach. Counseling might be perceived as a medicalized model by some individuals who would not see it as self-care. Other understandings of self-care might see a completely individual method of reflection as more beneficial for them. However, organizations should consider the benefits of having more than one self-care practice available to employees.

To talk of self-care in terms of right and wrong is to overlook the profound impact it can have on individuals and organizations. However, holding self-care as incorruptible is also to ignore the ways in which it can easily become a means to a more productive end. Participant 2 shared that the best way forward would be to integrate strategies that were based in a "colleagueto-colleague culture" and in peer support. Regardless of how organizations may choose to proceed, individuals can start by supporting their peers in their practices of self-care. 


\section{Limitations of Study}

First and foremost, this study is by no means comprehensive. This study used a small sample size; although a small sample size is not necessarily a limitation, the participants represented do not reflect the complete breadth of non-profit organization experience. Any suggestions or experiences provided in this study cannot be conclusively be applied to the sector as a whole, nor can they function as a checklist to better integrate self-care in all organizations. Additionally, as all participants are from different types and sizes of organizations within the broader category of "women-focused or feminist non-profit organization", any conclusions from the study are not reflective of the sector as a whole. All participants were also employed fulltime at their organizations - as indicated in this project, self-care experiences in the workplace may be very different between full- and part-time employees. Furthermore, a future study would unpack the reactions, strategies, and experiences related here across different understandings of woman. Self-care practices may be very different across race, gender, and class; this study does not reflect the full scope of concerns, possibilities, and successes that self-care may bring to the employees of feminist non-profit organizations. The purpose of this study is not to make any conclusive claims, but rather to provide a jumping off point for a broader discussion of self-care within the sector as a whole, and particularly within women-focused or feminist non-profits.

As this study is limited in scope, there are many potential future directions for research. Participant 5 highlighted humanitarian aid as an aspect of the non-profit sector where an investigation of self-care might be both timely and necessary. Future research on specific communication and knowledge mobilization strategies on self-care and tacit or explicit knowledge might offer the sector a more comprehensive roadmap to better communicating selfcare in the workplace — or it may further complicate the tensions between individual, 
spontaneous and organic discussions and practices of self-care and traditional organizational hierarchies and processes. 


\section{Conclusion}

In March 2017, social media news giant BuzzFeed published "30 Self-Care Tips That Are So Extra They Just Might Work" (Borges). The recommendations included such phrasing as "order everything you want from your favorite delivery place, plus enough for leftovers tomorrow" and "buy yourself a fancy-ass robe and sit around drinking tea out of a goblet like some decadent royal" (Borges, 2017). Fourteen out of those 30 tips advocated spending money in some way. This is not the self-care that participants in this project on feminist non-profit organizations talked about. This is not the political warfare to which Lorde referred as she critiqued the whiteness of traditional medical care and capitalism or advocated instead for selfcare.

This project provides five snapshots of how self-care is communicated in a feminist nonprofit organizations. These conversations did not complicate the differences in self-care communication across definitions of feminist or woman, nor do they fully represent the nonprofit sector. Participants have provided a glimpse at where organizations might incorporate selfcare in the future. While data collected for this project did not always neatly answer the research questions that guided this study, a more salient question emerged through examination of the data. Over the course of examining participant experience of guilt over self-care practices; how society and feminism interact around the topic of self-care; the ways in which donororganization relationships, overtime, and benefits affect self-care; and how organizations can improve their self-care policy and practice, an overarching question emerged of how or even if a personal, anti-establishment form of care could be practiced in an organization. Participant experience tended to show that the non-profit sector is grappling with serious structural challenges such as funding, marginalization within feminist movements, and continuing to take 
on increased work as government relinquishes it. Participants also intimated that it might be a long time before these issues could subside enough for self-care to be a worthy focus. Furthermore, if self-care is integrated in a heavy-handed, top-down approach, can it still be considered effective? Although participant experience did not highlight individual responsibility, a personal, anti-establishment form of self-care would certainly be complicated if the individual is expected to practice that self-care on their own time without support from an organization.

A more optimistic response would be to say that such a form of care is possible - through the drive and dedication of individuals. Participant 4's organization is proof that a strategic plan inclusive of self-care can be achieved as a result of engaged employees. Participants shared so many suggestions of what might be an ideal inclusion of self-care in the workplace: employees already know how their organizations can do better. However, the question remains whether employees should have to take up that advocacy—even as they may be already burning out. There remains a tension between individual responsibility and organizational responsibility in terms of self-care. While asking individual employees to practice self-care on their own time and their own dime is not the solution, neither are organizational mandates that turn self-care into a tick box. As noted, self-care as a concept which developed collectively through discussions about what constitutes care-indicating that a complete separation between individuals and community may never be possible. Furthermore, integrating self-care into policy undermines the value of the conversation as a form of professional communication —which participants showed is currently in existence and effective in many ways. Self-care in a workplace already complicates what we tend to think of as "professional"; perhaps an improved integration of selfcare practice will require forms of professional communication that break down what we tend to think of as "traditional" professional communication. Ultimately, this project hopes to provide a 
starting point for broader discussions of self-care within feminist non-profits. Whether it can become a perfect personal, anti-establishment form of self-care or not, employees of feminist non-profit organizations are the knowledge keepers of potentially better ways forward. Those better ways are not what Buzzfeed would consider self-care—-but participants and Buzzfeed did not tie Audre Lorde to self-care either. Non-profit organizations who wish to begin a discussion of self-care might consider Lorde's writing and the idea of self-care as political warfare as a starting place. After all, remembering the past is the only way to move forward. 


\section{References}

Baines, D., Charlesworth, S., Cunningham, I., \& Dassinger, J. (2012). Self-monitoring, selfblaming, self-sacrificing workers: Gendered managerialism in the non-profit sector. Women's Studies International Forum, 35(5), 362-371.

https://doi.org/10.1016/j.wsif.2012.07.002

Bell, H., Kulkarni, S., \& Dalton, L. (2003). Organizational prevention of vicarious trauma. Families in Society, 84(4), 463-470.

Benz, M. (2005). Not for the profit, but for the satisfaction? - Evidence on Worker Well-Being in Non-Profit Firms. Kyklos, 58(2), 155-176. https://doi.org/10.1111/j.00235962.2005.00283.x

Bloomquist, K. R., Wood, L., Friedmeyer-Trainor, K., \& Kim, H.-W. (2016). Self-care and professional quality of life: predictive factors among MSW practitioners. Advances in Social Work, 16(2), 292-311.

Borges, A. (2017, March 26). 30 Self-Care Tips That Are So Extra They Just Might Work. Buzzfeed. Retrieved July 12, 2018, from https://www.buzzfeed.com/annaborges/extranesslevel-viktor-nikiforov.

Bressi, S. K., \& Vaden, E. R. (2017). Reconsidering self-care. Clinical Social Work Journal, 45(1), 33-38. https://doi.org/10.1007/s10615-016-0575-4

Brinkerhoff, J. M. (2002). Government-nonprofit partnership: a defining framework. Public Administration and Development, 22(1), 19-30. https://doi.org/10.1002/pad.203

Coles, T. (2018, January 11). Self-care resolutions that have nothing to do with going to the gym. Huffington Post. Retrieved January 14, 2018, from http://www.huffingtonpost.ca/2018/01/09/self-care-resolutions_a_23328605/

Coster, J. S., \& Schwebel, M. (1997). Well-functioning in professional psychologists. Professional Psychology: Research and Practice, 28(1), 5-13. http://dx.doi.org.ezproxy.lib.ryerson.ca/10.1037/0735-7028.28.1.5

English, L., \& Peters, N. (2011). Founders' syndrome in women's nonprofit organizations: Implications for practice and organizational life. Nonprofit Management and Leadership, 22(2), 159-171. https://doi.org/10.1002/nml.20047 
Gallucci, N. (2017, 16 December). A totally doable, not so intimidating self-care survival guide to 2018. Mashable. Retrieved January 14, 2018, from

http://mashable.com/2017/12/16/self-care-guide-2018/

Gelder, S. van. (2016). The radical work of healing: Fania and Angela Davis on a new kind of civil rights activism. YES! Magazine. Retrieved from

http://www.yesmagazine.org/issues/life-after-oil/the-radical-work-of-healing-fania-andangela-davis-on-a-new-kind-of-civil-rights-activism-20160218

Hansmann, H. B. (1980). The role of nonprofit enterprise. The Yale Law Journal, 89(5), 835901. https://doi.org/10.2307/796089

Haraway, D. (1988). Situated knowledges: The science question in feminism and the privilege of partial perspective. Feminist Studies, 14(3), 575-599. https://doi.org/10.2307/3178066

Kamerāde, D., \& McKay, S. (2014). Is there a subjective well-being premium in voluntary sector employment? Voluntas, 26(6), 2733-2754.

Kisner, J. (2017, March 14). The politics of conspicuous displays of self-care. The New Yorker. Retrieved from https://www.newyorker.com/culture/culture-desk/the-politics-of-selfcare

Lorde, A. (1988). A burst of light: essays. Ithaca, N.Y: Firebrand Books.

Malinowski, A. J. (2014). Self-care for the mental health practitioner: The theory, research, and practice of preventing and addressing the occupational hazards of the profession. London: Jessica Kingsley. Retrieved from http://ebookcentral.proquest.com/lib/ryerson/detail.action?docID=1768915

Mulkeen, M. (2018, April 3). Queer Eye's Jonathan Van Ness on how to make a self-care "moment" wherever you are. GQ. Retrieved April 9, 2018, from https://www.gq.com/story/jonathan-van-ness-how-to-make-a-self-care-moment.

Nobel Women's Initiative, \& Match International Women's Fund. (2017). Strengthening Women's Rights Organizations Through International Assistance. Nobel Women's Initiative. Retrieved from https://nobelwomensinitiative.org/wpcontent/uploads/2017/06/REPORT-Strengthening-Women\%E2\%80\%99s-RightsOrganizations-Through-International-Assistance-WEB.pdf

Paget, M. (1983). Experience and knowledge. Human Studies, 6(1), 407-407. https://doi.org/10.1007/BF02127772 
Perez, S. (2018, April 2). Self-care apps are booming. Tech Crunch. Retrieved April 9, 2018, from http://social.techcrunch.com/2018/04/02/self-care-apps-are-booming/

Ramsden, C. (2016, September 9). Self-care in a digital space. OpenDemocracy. Retrieved April 9, 2018, from https://www.opendemocracy.net/5050/ch-ramsden/self-care-in-digital-space

Rasmussen, K., Malloy, D., \& Agarwal, J. (2003.) The ethical climate of government and nonprofit organizations: Implications for public-private partnerships. Public Management Review, 5(1), 83-97. https://doi.org/10.1080/1461667022000028825

Rich, Adrienne. (1983.) Sources. Hayek Press.

Rottenberg, C. (2014). The rise of neoliberal feminism. Cultural Studies, 28(3), 418-437. https://doi.org/10.1080/09502386.2013.857361

Salamon, L. M. (1995). Partners in public service: government-nonprofit relations in the modern welfare state. Baltimore, Md: Johns Hopkins University Press.

Shannon, P. J., Simmelink-McCleary, J., Im, H., Becher, E., \& Crook-Lyon, R. E. (2014). Developing self-care practices in a trauma treatment course. Journal of Social Work Education, 50(3), 440-453. https://doi.org/10.1080/10437797.2014.917932

Smith, S. R., \& Lipsky, M. (1993). Nonprofits for hire: the welfare state in the age of contracting. Cambridge, Mass: Harvard University Press.

Strauss, A. L., \& Corbin, J. M. (1990). Basics of qualitative research: grounded theory procedures and techniques. Newbury Park, Calif: Sage Publications.

Wax, S. (2018, 10 January). These are the Lonny editors' self-care rituals. Lonny. Retrieved January 14, 2018, from http://www.lonny.com/Lonny+Loves/articles/trwRVz7QiEc/These+Lonny+Editors+Self+ Care+Rituals

Weisberg, M., \& Dent, E. (2016). Meaning or money? Non-profit employee satisfaction. Voluntary Sector Review, 7(3), 293-313. http://dx.doi.org.ezproxy.lib.ryerson.ca/10.1332/096278916X14767760873899 


\section{Appendix A: Interview Guide}

1. How would you define self-care? What does it mean to you?

a. Rephrase: what does the term self-care mean? Signify?

b. Prompt: How do you practice self-care?

2. This research is looking at self-care in an organizational context, you can answer these questions in relation to any workplace you've been in-Does your organization discuss self-care?

a. Follow-up: If so, how?

b. Rephrase: Do you talk about self-care at work? Related to work?

c. Prompt: At a former org?

d. If not talked about: Why do you think that is?

3. When did your organization first start talking about self-care?

a. Rephrase: has this always been something that your organization talked about or is this new? If new, when did it come up?

b. Follow-up: are there any documents used at your workplace regarding self-care? Is there a formal document about self-care in the workplace? Who created this document? Any trainings (offered by your org or by someplace else?)

4. Around what issues is self-care brought up in your workplace?

a. Rephrase: when do you talk about self-care? Why do you talk about self-care in the workplace?

b. Follow-up/prompt: Face to face? In person? Email? Meetings? HR related? Content of the work? Funding concerns?

c. If no to Q2: when would you like to see self-care brought up?

5. Who is involved in conversations about self-care in your workplace?

a. Specific teams? Senior staff? Whole org?

b. Follow-up: who is leading those discussions? Who is not participating?

6. Do you feel that self-care is important? Does your workplace put the same level of importance on self-care as you do?

a. Rephrase: do you share the same viewpoint on self-care as your workplace?

7. Do you talk about self-care outside of work? How do those conversations differ? 
8. Are there additional ways you might discuss self-care in the workplace? Is anything missing from how it is currently being addressed? What is going well?

9. Anything else you would like to share about self-care in the workplace/your organization that you feel is significant to this project?

If no self-care discussed:

1. Why do you think that is?

a. Too busy?

b. Why is it not important?

c. Do you have an awareness of it?

d. Do you think your colleagues have an awareness of it anyway?

2. Have you ever felt that a discussion of self-care was missing/lacking?

3. Do you discuss self-care in your personal life?

4. How do you think those conversations might translate to a workplace setting? Would they translate? 